\title{
NORM INEQUALITIES FOR SOME ONE-SIDED OPERATORS
}

\author{
DAH-CHIN LUOR
}

Abstract. We show that the one-sided maximal operators associated with Borel measures are of strong type $(p, p), 1<p<\infty$, with constant $p^{*}$, and the related one-sided geometric maximal operators are of strong type $(p, p), 0<p<\infty$, with constant $e^{1 / p}$. We also investigate norm inequalities for integral operators with three measures on the cone of nonnegative nonincreasing functions. Our results show that if we restrict the measures in the inequalities to some particular classes, then a simple characterization for these inequalities to hold can be obtained.

Mathematics subject classification (2010): Primary 26D15; Secondary 26D10, 42B25.

Keywords and phrases: Hardy's inequality, weighted inequalities, norm inequalities, integral operators, maximal operators, geometric maximal operators.

\section{REFERENCES}

[1] K. F. ANDERSEN, Weighted inequalities for maximal functions associated with general measures, Trans. Amer. Math. Soc. 326 (1991), 907-920.

[2] K. F. Andersen, Weighted generalized Hardy inequalities for nonincreasing functions, Canad. J. Math. 43 (1991), 1121-1135.

[3] M. A. ARIÑ̃ AND B. MucKenhoupt, Maximal functions on classical Lorentz spaces and Hardy's inequality with weights for nonincreasing functions, Trans. Amer. Math. Soc. 320 (1990), 727-735.

[4] G. BennetT And K.-G. Grosse-Erdmann, Weighted Hardy inequalities for decreasing sequences and functions, Math. Ann. 334 (2006), 489-531.

[5] A. Bernal, A note on the one-dimensional maximal function, Proc. Roy. Soc. Edinburgh Sect. A 111 (1989), 325-328.

[6] M. J. CARro, J. A. Raposo, AND J. Soria, Recent developments in the theory of Lorentz spaces and weighted inequalities, Mem. Amer. Math. Soc. 877 (2007).

[7] M. J. CARRo AND J. Soria, Boundedness of some integral operators, Canad. J. Math. 45 (1993), $1155-1166$.

[8] M. J. CARro And J. Soria, Weighted Lorentz spaces and the Hardy operator, J. Funct. Anal. 112 (1993), 480-494.

[9] J. Cerdà And J. Martín, Weighted Hardy inequalities and Hardy transforms of weights, Studia Math. 139 (2000), 189-196.

[10] D. CRuZ-URibe, The minimal operator and the geometric maximal operator in $\mathbb{R}^{n}$, Studia Math. 144 (2001), 1-37.

[11] D. Cruz-Uribe And C. J. Neugebauer, Weighted norm inequalities for the geometric maximal operator, Publ. Mat. 42 (1998), 239-263.

[12] A. Gogatishvili, A. Kufner, And L.-E. Persson, Some new scales of weight characterizations of the class $B_{p}$, Acta Math. Hungar. 123 (2009), 365-377.

[13] G. H. Hardy AND J. E. LitTlewood, A maximal theorem with function-theoretic applications, Acta Math. 54 (1930), 81-116.

[14] H. Heinig And L. MaligRAnda, Weighted inequalities for monotone and concave functions, Studia Math. 116 (1995), 133-165.

[15] E. Hewitt And K. Stromberg, Real and abstract analysis, Springer, New York, 1965.

[16] M. Johansson, A new characterization of the Hardy and its limit Pólya-Knopp inequality for decreasing functions, Internat. Ser. Numer. Math. 157 (2008), 97-107. 
[17] M. Johansson, V. D. STEPANOV, And E. P. UshaKova, Hardy inequality with three measures on monotone functions, Math. Inequal. Appl. 11 (2008), 393-413.

[18] A. Kufner And L.-E. Persson, Weighted inequalities of Hardy type, World Scientific Publishing Co., Singapore/New Jersey/London/Hong Kong, 2003.

[19] S. LAI, Weighted norm inequalities for general operators on monotone functions, Trans. Amer. Math. Soc. 340 (1993), 811-836.

[20] E. R. Love, Inequalities related to those of Hardy and of Cochran and Lee, Math. Proc. Cambridge Philos. Soc. 99 (1986), 395-408.

[21] L. Maligranda, Weighted inequalities for monotone functions, Collect. Math. 48 (1997), 687-700.

[22] L. MALigranda, Weighted inequalities for quasi-monotone functions, J. London Math. Soc. 57 (1998), 363-370.

[23] F. J. Martín-Reyes, P. Ortega Salvador, and A. De la Torre, Weighted inequalities for one-sided maximal functions, Trans. Amer. Math. Soc. 319 (1990), 517-534.

[24] E. A. Myasnikov, L.-E. Persson, AND V. D. StePanov, On the best constants in certain integral inequalities for monotone functions, Acta Sci. Math. (Szeged) 59 (1994), 613-624.

[25] C. J. NeUgebauer, Weighted norm inequalities for averaging operators of monotone functions, Publ. Mat. 35 (1991), 429-447.

[26] C. J. Neugebauer, Some classical operators on Lorentz space, Forum Math. 4 (1992), 135-146.

[27] L.-E. Persson, O. V. Popova, And V. D. Stepanov, Two-sided Hardy-type inequalities for monotone functions, Complex Var. Elliptic Equ. 55 (2010), 973-989.

[28] L.-E. Persson, V. D. Stepanov, And E. P. Ushakova, Equivalence of Hardy-type inequalities with general measures on the cone of non-negative respective non-increasing functions, Proc. Amer. Math. Soc. 134 (2006), 2363-2372.

[29] P. O. Salvador And C. R. Torreblanca, Weighted inequalities for the one-sided geometric maximal operators, Math. Nachr. 284 (2011), 1515-1522.

[30] E. SAWYER, Weighted inequalities for the one-sided Hardy-Littlewood maximal functions, Trans. Amer. Math. Soc. 297 (1986), 53-61.

[31] E. SAWYER, Boundedness of classical operators on classical Lorentz spaces, Studia Math. 96 (1990), $145-158$.

[32] X. SHI, Two inequalities related to geometric mean operators, J. Zhejiang Teacher's College 1 (1980), $21-25$.

[33] G. Sinnamon, Hardy's inequality and monotonicity, In: Function Spaces, Differential Operators and Nonlinear Analysis, Mathematical Institute of the Academy of Science of the Czech Republic, Prague, 2005, 292-310.

[34] V. D. StePanov, The weighted Hardy's inequality for nonincreasing functions, Trans. Amer. Math. Soc. 338 (1993), 173-186.

[35] V. D. Stepanov, Integral operators on the cone of monotone functions, J. London Math. Soc. 48 (1993), 465-487.

[36] X. Yin AND B. Muckenhoupt, Weighted inequalities for the maximal geometric mean operator, Proc. Amer. Math. Soc. 124 (1996), 75-81. 